\title{
Migración chilota en Magallanes: Una lectura sociológica de la diferenciación social*
}

\author{
Chiloé migration in Magallanes: A sociological \\ reading of social differentiation
}

Migração chilota na região de Magalhães: Uma leitura sociológica da diferenciação social

José Jorquera Navarro** , Matías Jaramillo***

\section{RESUMEN}

En este artículo se presenta una lectura sociológica de dimensioPalabras nes de la diferenciación social que vivencian los y las migrantes clave: Chiloé, internas de Chiloé en Magallanes. A través de entrevistas cualitativas a migrantes llegados antes de 1980, se identifican dimensiones históricas y sociales de los procesos de inserción en una diferenciación social, Magallanes, migración interna. sociedad diferente y cómo se materializa el ser chilote, lo que tiene efectos hasta el día de hoy. Se considera que las tradiciones conceptuales que describen la construcción de un otro a través de la noción de extranjero y migrante generan importantes rendimientos analíticos para procesos de migración interna y, a partir de ello, se concluye que la diferenciación y discriminación de chilotes en Magallanes tiene un carácter más latente que manifiesto, pero estable en el tiempo que se reproduce hasta la actualidad.

\section{ABSTRACT}

This article intends to present a sociological reading of the dimenKeywords: sions of social differentiation experienced by internal migrants

* Este artículo nace a partir de la tesis de pregrado de Sociología de Jorquera (2016).

** Chileno, Sociólogo de la Universidad de Chile. Universidad Tecnológica Metropolitana, Santiago, Chile. E-mail: j.ignacio.jorquera@gmail.com

*** Chileno. Magíster en Ciencias Sociales de la Universidad de Chile. Estudiante de Doctorado en Ciencias Sociales de la Universidad de Chile financiado por ANID. Beca doctorado nacional № 21201772. E-mail: matijaramillorojas@gmail.com 
from Chiloé in Magallanes. Through qualitative interviews with migrants who arrived before 1980, we identify the historical and social dimensions of insertion processes into a different society and how the Chiloé being is materialized, which has effects until today. We consider the conceptual traditions that describe one another's construction through foreigner and migrant notions to generate significant analytical yields for internal migration processes. We conclude that the differentiation and discrimination of Chilote people in Magallanes have a more latent than manifest character, but stable over time reproduced up to the present.

\section{RESUMO}

Este artigo visa apresentar uma leitura sociológica das dimensões da diferenciação social experimentada pelos indivíduos que praticaram a migração interna entre Chiloé e a região de Magalhães. Através da realização de entrevistas qualitativas aos migrantes que chegaram antes de 1980, são identificadas dimensões históricas e sociais dos processos de inserção em uma sociedade diferente e como se materializa o ser chilote, o que possui efeitos até os dias de hoje. Considera-se que as tradições conceituais que descrevem a construção de um outro através da noção de estrangeiro e migrante geram importantes rendimentos analíticos para os processos migratórios internos e, a partir disso, conclui-se que a diferenciação e discriminação dos chilotes em Magalhães apresenta um caráter mais latente do que manifesto, porém estável no decorrer do tempo e que se reproduz até a atualidade. differentiation, Magallanes, Internal migration.

Palavraschave: Chiloé, diferenciação social, Magalhães, migração interna. 


\section{Introducción}

Desde los años 90, en torno a la apertura democrática de Chile, la temática migratoria ha estado presente en diversas producciones de la ciencia social en general y de la sociología en particular. El interés ha ido creciendo y se observa que continuará profundizándose (Cano y Soffia, 2009), especialmente por la dinamización y complejización del patrón migratorio chileno que se consolida en 2019 como uno de los principales países de destino de Sudamérica, cuya tendencia no parece disminuir (Instituto Nacional de Estadísticas, INE y Departamento de Extranjería y Migración, DEM, 2019).

Sin embargo, los estudios de la migración tienen otra dimensión con importantes intereses para la investigación de las relaciones sociales: la migración interna. La Comisión Económica para América Latina y el Caribe, CEPAL (2020) la caracteriza como un elemento determinante en los procesos de redistribución espacial de la población y que tiene implicaciones para comunidades, hogares y personas, produciendo efectos sociales, culturales y económicos.

Si bien ha habido distintos esfuerzos académicos por caracterizar histórica y socialmente la migración interna (Rodríguez Vignoli, 2019), este artículo pretende ser un aporte para un acercamiento comprensivo de los procesos de significaciones simbólicas acerca de una dimensión específica: la diferenciación social. A partir de entrevistas en profundidad y de un análisis cualitativo de información producida de forma primaria, se pretende caracterizar el discurso de habitantes chilotes en Magallanes en cuanto a su proceso de movilidad interna dentro de Chile y cómo se observan los efectos - tanto territoriales como sociales- de la inserción de esta importante población, que sigue siendo fundamental para caracterizar la región más meridional del continente.

Magallanes como territorio, tiene potencial de avanzar hacia una interculturalidad (Walsh, 2008), es decir, como un espacio donde distintos saberes culturales se comunican para configurar las relaciones e interacciones sociales: chilenos, croatas y chilotes, entre otros, que han ido dotando los estudios sociológicos de especificidad y de relevancia para acercarse a la comprensión de la sociedad.

La inmigración, sea interna o internacional, está fuertemente vinculada con la constitución de un otro que evidencia conflictos dentro 
de una sociedad (Margulis, 1997). El discurso de los sujetos que representan a la sociedad puede articular ese otro en estigmas de alteridad basados en prejuicios y estereotipos (Correa, 2011; Goffman, 2006; Tijoux, 2014), y que condiciona su lugar excluido.

Para comprender el proceso migratorio chilote se propone situarlo dentro de la conformación nacional y la constitución de identidades culturales (Correa, 2011) y cómo se relaciona con las ideas que existen acerca de la/el extranjero y la/el inmigrante ${ }^{4}$.

Este fenómeno particular de migración se vincula directamente con la configuración de las naciones latinoamericanas (Margulis y Urresti, 1999) y la nación chilena, con procesos donde se establecen diferenciaciones de clase y que permite legitimar posiciones de poder. Dichos procesos aluden a la negación cultural e identitaria del que se considera otro desde la conquista (Calderón et al., 1996), asociados con una exclusión social histórica de ciertos personajes ideales: la mujer, el indio, el negro, el mestizo, el campesino y - para este casola/el inmigrante pobre. En la constitución de clases y articulación de hegemonías de las naciones, se establecieron clasificaciones sociales y modelos culturales que atribuyeron superioridad o inferioridad, "privilegiando y legitimando atributos vinculados con un sector de la población y cargando con rasgos negativos a otros sectores" (Correa, 2011, p. 33). Las clases altas se vincularán con un arquetipo europeo, una noción de desarrollo y progreso; en tanto que el tipo indígena o mestizo se asociará con la noción de subdesarrollo y barbarie.

En ese sentido, Paul Singer $(1988 ; 2003)$ expone que las migraciones son posibles de comprender desde ciertos procesos históricos que las condicionan, y dentro de todo un cambio global, desde donde no se pueden separar. Asimismo, el análisis sistema-mundo de Wallerstein $(1974 ; 2005)$ plantea que ciertas economías más desarrolladas necesitan mano de obra de otro punto geográfico que tenga un menor desarrollo económico. Sin embargo, al producirse este movimiento humano, la/el inmigrante pierde gran parte de su modo de vida tradicional y de su identidad, cuestión que se relaciona directamente con el aspec-

4 La Revista Temas Sociológicos ha respetado en la edición de este artículo este uso, en lugar del masculino genérico privilegiado por la RAE para referirse a la clase que corresponde a todos los individuos de la especie, sin distinción de sexos. 
to de readaptación, y que concierne a la sociedad receptora, en tanto esta construye su identidad a partir de un tipo ideal de nación y raza (Wallerstein y Balibar, 1988), donde se excluiría al extranjero.

Por otro lado, desde las distintas teorías de la subjetivación y de la identidad, lo esbozado por Simmel (1939), Goffman (2006) y Schütz (1974) mantienen un correlato con lo planteado por Wallerstein (1974; 2005) y Singer (1988; 2003), respecto de cómo cada sociedad se autoconstituye a partir de la diferencia con el otro, del que no forma parte del tipo ideal de sujeto y es quien quedaría excluido del funcionamiento de la interacción; lo que se debería a que cumplen un rol de sacrificio, para poder mantener la armonía y el equilibrio en el grupo social. Esta última idea se puede reforzar en el caso de la migración chilota, en el proceso de construcción de la sociedad magallánica, pues estos serían parte de ella, pero juegan un rol diferenciado al que llevan otros actores, como lo fueron las/los migrantes europeos.

En investigaciones anteriores se han documentado distintas aproximaciones a la realidad de los migrantes chilotes en Magallanes.

A través una investigación etnográfica, Juan Manual Saldívar (2017) documenta la inmigración chilota en diversas dimensiones. Históricamente, constata que la mayor concentración se produjo entre 1930 y 1970 y que estos desplazamientos representan formas de transnacionalismo en relación con las dinámicas culturales, las fronteras geográficas y los lazos asimétricos que se construyeron en la Patagonia chilena y argentina. Así, se construyeron dinámicas de relaciones en las que se reproducen códigos identitarios más allá de las fronteras políticas en las que se desenvuelven. Lo que genera mantenimiento, incluso, de vínculos asiduos con sus lugares de origen a través del envío de remesas, redes multidireccionales y referencias simbólicas del terruño que representan Chiloé en Patagonia como un territorio compartido e interactuado (Saldívar, 2017).

El mismo autor aborda la subjetividad de los migrantes chilotes haciendo énfasis en la nostalgia o el duelo migratorio (Saldívar, 2018) que se representan en "circulación de mercancías y ensamblaje de tradiciones culturales en ambos lados de la frontera" (p. 509), estableciendo continuidades de tradiciones entre el lugar de origen y el de residencia de los migrantes, como por ejemplo, el ensamblaje religioso del Naza- 
reno de Caguach tanto en Punta Arenas en Chile como Río Gallegos en Argentina (Saldívar, 2019) como proceso transnacional de carácter religioso a propósito de la migración chilote hacia la Patagonia, o el rito fúnebre propio de Magallanes que demuestra la influencia chilota, pero a la vez los procesos de socialización con los magallánicos (Aguilar et al., 2012).

Desde la antropología de la memoria y con el método biográfico, Riveros Quinteros y Fernández Génova (2018) plantean que la identidad chilota en Magallanes es una construcción dinámica en el tiempo, consolidando una identidad como isleños y estableciendo características que los definen y diferencian del resto de la población magallánica. Las autores plantean que esta es una construcción de otredad que se observa en discriminaciones físicas y/o simbólicas en su proceso de inserción social y también económicas atribuidas justamente al choque de las identidades, cuestión que estuvo en silencio u oculta, pero que actualmente "la memoria social del pueblo chilote en Punta Arenas ha transitado desde una dimensión subterránea hasta disputar un espacio de reconocimiento en el ámbito público y en la conformación de la identidad regional magallánica" (Riveros Quinteros y Fernández Génova, 2018, p. 160).

A partir de estos antecedentes, se puede constituir la noción del extranjero como otredad sobre la base de la diferenciación social, sin embargo, se propone además incorporar dimensiones de la historia y la demografía.

Debido a que la migración chilota no es reciente, sino que constituye uno de los principales pilares de la colonización de la sociedad magallánica, surgen las preguntas: ¿Existe una visibilidad mayor hacia la inmigración chilota (en comparación con el resto de las migraciones a la zona ${ }^{5}$ ? ¿Cómo fue la participación social de las y los chilotes en esta nueva sociedad magallánica?

Con entrevistas realizadas a migrantes chilotes llegados a Punta Arenas previamente a $1980^{6}$, se presentarán los resultados de un estu-

5 Migraciones internacionales, tales como: croata, italiana, española, suiza, entre otras.

6 En los siguientes apartados se explicará este corte en 1980, pero tiene relación con la fuerte baja de la migración chilota en Magallanes. 
dio descriptivo desde la perspectiva del interaccionismo simbólico que permita observar los conflictos culturales y de poder (Gadea, 2018), es decir, interpretar los significados de acciones y discursos de las personas situadas en su contexto de producción en tensión que, desde su lógica situacional, permite observar la sociedad en la que se inserta de modo integral.

\section{Migración chilota en Magallanes}

En la historia chilena, las migraciones internas se abordan principalmente por el traslado del campo a la ciudad, producto de los procesos de modernización y urbanización. Martínez Pizarro (1994) explica que "estos desplazamientos han constituido claras respuestas al devenir socioeconómico de los espacios nacionales, (...) asociados con el comportamiento de los mercados de trabajo regionales y la generación de empleo" (p. 19). Otro aspecto fundamental, es la preponderancia hasta fines de los 60 de la migración rural-urbana en el crecimiento de ciertas ciudades, activado por el modelo de sustitución de importaciones, llegando a representar un $40 \%$ del aumento de las poblaciones urbanas entre 1950 y 1960.

Las corrientes migratorias tienen como destino principal la provincia de Santiago, evidenciando flujos migratorios escalados, es decir, que las/los primeros inmigrantes se trasladan a ciudades más pequeñas para posteriormente llegar a la capital, donde este tipo de inmigrante representa más del 50\% del total (Gómez et al., 1981). Particularmente, sobre el extremo sur, esto es Aysén y Magallanes, Raczynski y Vergara (1978) describen que hacia 1960 los migrantes presentan una tasa migratoria neta positiva, pero de monto decreciente.

En ese sentido, a pesar de la condición periférica dentro del mercado nacional, Magallanes opera como núcleo de atracción por su desarrollo histórico como región exportadora hacia mercados internacionales (Ortega Perrier, 1980).

En cuanto a la relación con la población chilota, Urbina (2013) recopila las expediciones en la época colonial (desde el siglo XVI al siglo XVIII) realizadas a la Patagonia occidental, donde varias de estas zarpan desde Chiloé. Asimismo, según Mansilla Contreras (2012), durante el siglo XVIII se producen viajes por las costas de Aysén y Magalla- 
nes como parte de expediciones geográficas, avanzadas de misiones jesuitas y en búsqueda de enemigos de España. En particular, Marco Antonio León (2015) describe que estas travesías también se realizaron con fines económicos:

el desplazamiento de chilotes hacia los canales australes, no con fines de reconocimiento geográfico ni de colonización, sino más bien para explotar los recursos naturales de la zona tales como el guano, el aceite y los cueros de lobos marinos; productos que generaron un comercio considerable y un asentamiento espontáneo y temporal en la actual región de Aysén (pp. 60-61).

De esta forma, será hasta 1843 que la región es colonizada con la toma del Estrecho de Magallanes por parte de la Goleta Ancud, evento donde será posible situar a las/los primeros inmigrantes chilotes como parte de aquella expedición. El aumento de población chilota en Magallanes se produce en 1867. Es así que, fomentado por tres decretos del gobierno central, se otorgan ciertas garantías para los colonos: pasaje y equipaje libre, así como hectáreas de terreno según el grupo familiar (Muñoz Rau y Zamora Mondaca, 1975). Punta Arenas es declarada Puerto Libre y Menor, lo que produce la migración de 38 familias chilotas, llegando a representar el $70 \%$ de la población del territorio (Montiel, 2007; Muñoz Rau y Zamora Mondaca, 1975; Ortega Perrier, 1980). Por último, se inician nuevas actividades económicas como la agricultura, la explotación forestal, la pesca y el tráfico de indios, y posteriormente la extracción minera de carbón y oro; en 1877 se decide llevar a la región una partida de ovinos, marcando el inicio de la actividad ganadera (Martinic, 2002).

En las siguientes décadas el proceso económico de la región se ve eclipsado por la explotación ganadera, gracias a esta actividad las/ los inmigrantes extranjeros acumulan grandes capitales y comienzan proyectos de explotación masiva. Así, se generó una gran demanda de mano de obra, lo que fomentó la migración estacionaria o faenera para la esquila de ovinos (Lausic, 2005; Muñoz Rau y Zamora Mondaca, 1975); además, la llegada de migrantes chilenos —entre ellos, chilotes - fue una medida tomada por el gobierno para inducir el crecimiento de la población nativa (Rodríguez Uribe, 2006), donde "Chilotes son los primeros pobladores de Puerto Toro en 1892, de Porvenir en 1894, de Puerto Prat en 1899 y sobre todo de Puerto Natales en 1911 
... son los inmigrantes temporales que desde principios del siglo XX acuden a la esquila" (Urbina, 1988, p. 42). En concreto, lo que se produjo fue un proceso de sustitución laboral desde 1907, que reemplazó la mano de obra inmigrante de chilotes por europeos, dado que estos adquirieron una mejor posición socioeconómica (Montiel, 2007).

Cabe destacar el fenómeno conocido por la fiebre del oro entre finales del siglo XIX y comienzos del XX, donde en ciertas zonas de Tierra del Fuego trabajadores chilotes y yugoslavos (impulsados por Julius Popper $^{7}$ ) exploraron y extrajeron grandes cantidades de oro, que luego comercializaron en Argentina y Europa (Saldívar y Terrado, 2019). Esto produjo que algunos chilotes fundaran empresas auríferas, en formato de pirquineros que realizaban trabajos de noviembre a marzo.

Las primeras décadas del siglo XX son denominadas la edad de oro de Magallanes (Martinic, 1992), debido a su expansión económica, lo que se ve reflejado en que desde 1875 y hacia 1900 se triplicara la población de Punta Arenas hasta llegar a cerca de 17.330 habitantes, de los cuales el $26,17 \%$ eran inmigrantes chilotes (Ortega Perrier, 1980) y un cuarto de este porcentaje correspondiera a origen extranjero (Lausic, 2005). Paralelamente, existe un gran flujo emigratorio de población joven de Chiloé — de forma temporal o definitiva-, facilitado por líneas de vapores que unen Castro con Aysén y Punta Arenas (Urbina, 1988).

En relación con las características de las/los migrantes chilotes, estos habitantes provienen de una historia campesina, donde la mayoría era propietaria de tierras, es decir, minifundistas dedicados al monocultivo de la papa, bajo una economía de autoconsumo (Lausic, 2005; Muñoz Ru y Zamora Mondaca, 1975). Por ejemplo, Urbina (2002) señala que para principios de 1900 Chiloé era la provincia más ruralizada del país. Esta presencia de pobreza en términos de salario, fomenta su emigración hacia Magallanes, lo que se refuerza ante la falta de un proyecto económico para la zona chilota (Lausic, 2005). Una muestra de ello es que la población de Chiloé disminuyó drásticamente en los años 30 en un 17,55\%, lo que "coincide con el alza de población Aysén y Magallanes" (Mancilla y Rehbein, 2009, p. 3). Aun así, estas cifras no

7 Personaje histórico de la Patagonia, reconocido por ser uno de los principales responsables del exterminio del pueblo selk'nam. 
se traducen directamente en un aumento de la población magallánica, puesto que al verse copada la demanda de trabajo en la zona, las/ los inmigrantes chilotes se trasladan a las ciudades argentinas (Lausic, 2005).

En ese sentido, las migraciones chilotas se fueron realizando por lentas etapas sucesivas, en las que el hombre viajaba a trabajar a las estancias, para después regresar cada año en invierno a Chiloé, proceso que se repetía en la temporada de esquila (noviembre a febrero), hasta que el emigrante-ovejero comenzaba a trasladarse y permanecer más tiempo en Punta Arenas o en Puerto Natales ${ }^{8}$.

Se destaca en un comienzo la migración estacionaria del hombre chilote, para posteriormente (en algunos casos) emigrar la familia y establecerse definitivamente en Magallanes, elemento muy común en las migraciones de todo tipo. Esto, igualmente lo señala un entrevistado en el estudio de Saldívar (2018), ya que "entre las décadas de 1930 y 1950 la tradición migratoria hacia el sur era muy fuerte porque en Chiloé no había trabajo y nos teníamos que ir a la Patagonia" (p. 505). Además, los distintos lugares de asentamiento variaban según el auge laboral: "explotación pastoril que incluía esquila y frigorífico en regiones de Santa Cruz y Tierra del Fuego, minería en Río Turbio, petróleo en Comodoro Rivadavia y construcción de casas habitacionales en regiones de Tierra del Fuego" (Saldívar, 2017, p. 183); donde se producen rotaciones de los migrantes ${ }^{9}$, como especies de circuitos transfronterizos entre Argentina y Chile. En específico, los migrantes de distintos lugares ${ }^{10}$ se reunían en grupos de comparsas para viajar hacia la Patagonia, donde eran integrados con diversos oficios: velloneros (que sacaban el vellón de la oveja), esquiladores, prenseros (que juntaban la lana), cocineros; ente otros (Saldívar, 2019). La Patagonia pasa a ser una tierra prometida en el imaginario histórico chilote y que persiste hasta la actualidad (Saldívar, 2017).

8 Tal como indica Manuel Rodríguez en su libro de 2004, titulado Colonos, gañanes y peones. Historia del trabajo y los trabajadores en Magallanes y la Patagonia, el cual se puede obtener en el siguiente enlace: https://surhistoria.wordpress.com/2020/09/15/historia-del-trabajo-y-los-trabajadores-en-magallanes-y-la-patagonia-1843-1973-ensayo/

9 Se habla en masculino, por lo mencionado previamente.

10 Se observan distintas ciudades, pueblos o localidades de Chiloé: Ancud, Castro, Quemchi, Chonchi, Caguach, Curaco de Vélez, Dalcahue, Quellón y Queilén, por nombrar algunas (Aguilar et al., 2012). 
A pesar de que en 1945 se descubre el primer yacimiento petrolífero en la región, como plantea Ortega Perrier (1980), los años 50 la zona deja de constituir un atractivo para la migración, experimentando movimientos emigratorios, lo que se habría producido por la crisis económica de 1946-1947, llegando a perder 6.500 habitantes (Martinic, 1988). En contraposición, Saldívar (2018) recopila que en este período una plaga de tizón ${ }^{11}$ afecta las plantaciones de papas en Chiloé, provocando una importante crisis económica, lo que impulsa las migraciones al sur austral. De igual modo, del 95\% de población chilena presente en la zona, cerca de un $28 \%$ procedía de Chiloé, manteniéndose como el mayor polo de inmigración en la región. Para 1960, Raczynki (1978) señala que la mayor cantidad de inmigrantes provienen de Chiloé, con una representación del 10,23\% (5.424 inmigrantes) de la población. Además, la emigración chilota a Magallanes corresponde al $45,14 \%$ de un total de emigrantes en Chiloé (12.015 emigrantes). Esto se relaciona con la última oleada migratoria chilota importante, que Montiel (2007) señala que ocurrió pasada la mitad de los años 50, situación acentuada a consecuencia del terremoto de Valdivia de 1960, que provocó un éxodo poblacional hacia el sur. Luego, para 1970 la inmigración chilota continúa siendo la mayor en Magallanes con un 5,11\% (3.476 inmigrantes); además, las/los chilotes corresponden al $34,26 \%$ del total de inmigrantes (10.153 inmigrantes). En relación con la emigración chilota a Magallanes, esta corresponde a un 45,98\% del total de emigrantes (7.559 emigrantes).

Los datos aportados por Muñoz Rau y Zamora Mondaca (1975), verifican el alto porcentaje de población chilota en Magallanes, pero que va disminuyendo a medida que pasan las décadas, producto del propio crecimiento poblacional de la región, así como por la disminución como polo de inmigración posterior a 1970. Según dicho estudio "el $53,55 \%$ (...) de la población activa chilota es obrera (...) Significativo es el papel de la mujer que representa casi en forma exclusiva al trabajador en la categoría 'Empleado Doméstico' y que constituyen el 39,46\% del total de la provincia" (Muñoz Rau y Zamora Mondaca, 1975, p. 147).

En resumen, la migración se hizo una constante entre la década del 30 hasta mediados de los 70, donde la esquila fue el sector de mayor

11 Es un parásito de plantas, que infecta principalmente a tubérculos. 
concentración laboral chilota (Saldívar, 2019). De esta manera, es posible considerar cinco etapas migratorias, de las cuales las cuatro últimas son planteadas por Saldívar y Terrado (2019):

- la primera, desde la toma del Estrecho de Magallanes en 1843 hasta mediados del 1870, donde se ve impulsada por las medidas tomadas por el gobierno chileno;

- la segunda de 1884 a 1909, referente a la fiebre del oro en Tierra del Fuego;

- la tercera, con mayor intensidad después de la década del 20 con el apogeo de la industria ganadera;

- la cuarta, posterior a la década del 30, donde los chilotes cumplían el servicio militar en Punta Arenas y. posteriormente. se establecían en diferentes sectores laborales; $\mathrm{y}$

- la última, entre los años 50 y 80, donde las migraciones son más frecuentes debido a situaciones ocurridas en Chiloé y en el país, como la plaga del tizón, el terremoto de Valdivia de 1960 y el golpe estado de 1973.

En los años posteriores a 1980 hasta la actualidad existen escasos estudios acerca de la temática, lo que se explica, en parte, por la caída de la migración chilota, debido al establecimiento de empresas salmoneras en los mares interiores de Chiloé en la misma década, lo que generó una importante fuente de trabajo para los habitantes (Aguilar et al., 2012; Saldívar, 2019).

Por su parte, en el debate respecto de la historia y la identidad de Magallanes existen diversos estudios y discusiones académicas desde la historia y las ciencias sociales (Harambour, 2009; Lausic, 2005; Martinic, 1999; entre otros). No obstante, acerca de la migración chilota existe un número limitado de publicaciones académicas que traten el tema directamente. Se destacan dos tesis de pregrado de los geógrafos Juan Muñoz y Enrique Zamora (1975) y la antropóloga Marietta Ortega Perrier (1980). De tal forma, el exiguo estudio desde las ciencias sociales no permite comprender el significado cultural que tiene y ha tenido el apelativo chilote en Magallanes ${ }^{12}$. Reciente-

12 Como bien señala Manuel Rodríguez en su libro de 2004 Colonos, gañanes y peones. Historia del trabajo y los trabajadores en Magallanes y la Patagonia, el cual se puede 
mente, y como se mencionaba en el apartado anterior, se encuentran las publicaciones de Riveros Quinteros y Fernández Génova (2018) y Saldívar $(2017 ; 2018 ; 2019)$.

\section{Aspectos metodológicos}

Para los propósitos investigativos fue necesario comprender los significados que las/los inmigrantes otorgan a las relaciones sociales que desarrollaron en su llegada y establecimiento en Magallanes, ya que ello permite desentrañar las experiencias vividas. Se plantearon cuatro dimensiones: hitos de la trayectoria migratoria, condiciones económicas y materiales, el discurso simbólico de su trayectoria migratoria y las principales redes de apoyo que crearon. Para efectos de este artículo, nos centraremos en la dimensión simbólica.

Estas dimensiones fueron analizadas por medio del relato de vida, lo que implicó aunar todos estos aspectos propios de la migración ya descritos en un proceso de vivencia del sujeto inmigrante. Esta herramienta metodológica fue utilizada de forma pionera en temas de migración por Thomas y Znaniecki (2006) al estudiar las trayectorias de las/los campesinos polacos a Estados Unidos a principios del siglo XX. El instrumento permitió expresar el manifiesto de la opinión colectiva en la experiencia del individuo, integrando biografía personal, historia y estructura social; a su vez comprender el movimiento de la sociedad magallánica e intentar describirla en profundidad. Además del carácter subjetivo de este material, se complementó con aspectos que estarían en un estrato social diferente de la experiencia del sujeto: esto es, el contexto económico global, nacional y regional del período, lo que permite combinar los cuerpos estudiados con las estructuras objetivas a las que se enfrentan (Camas, 2001). Es decir, el estudio estuvo enmarcado en la histórica tradición sociológica de vincular agencia y estructura, considerados como estratos de la realidad autónomos y no reductibles entre sí con poderes emergentes propios (Archer, 2009), con lo que se pretende tomar lo que Mills (1986) define como la promesa de la sociología: vincular las trayectorias personales con la historia de la sociedad para buscar comprensiones. 
Así, el interés por describir el proceso migratorio de las/los chilotes permitió reconstruir una historia olvidada por la historia regional y nacional. Es decir, comprender el modo en que ciertos hitos marcaron su trayectoria migratoria, tanto la forma en que fueron ascendiendo económica y socialmente, como las redes de apoyo que ayudaron a dicho proceso y de qué manera analizan su identidad chilota en torno a su identificación como el otro social.

Para abordar los discursos de las/los entrevistados, se incorporó la perspectiva biográfica desarrollada por Daniel Bertaux (1980) en la que "los relatos de vida constituyen una herramienta incomparable de acceso a lo vivido subjetivamente" (p. 2), pues es inevitable que emerja una fuente ilimitada de contenido debido al propio carácter de esta metodología y su base en las vivencias de los sujetos. Este autor reflexionó respecto del carácter estructural y simbólico de los estudios sociológicos y de cómo dan cuenta de la importancia de los relatos de vida, puesto que al proyectar el estudio desde una perspectiva subjetiva en su producción, se complementará con el carácter estructural de las trayectorias migratorias en el análisis. Esto último se explicaría porque lo social no sería algo fijo, sino más bien cambiante según las propias fuerzas que lo componen, siendo tanto el campo de estudio como el objeto de estudio; para Bertaux (1980) esto se traduce en unificar el estudio social de lo estructural (el campo de estudio) y lo simbólico (el objeto de estudio).

Esto toma relevancia para la investigación, en cuanto se comprende que la migración chilota a Magallanes responde a un entramado del contexto nacional que vivía Chile para principios del siglo XX, así como la región austral, por lo que este aspecto estructural es posible vislumbrarlo a partir de los significados de sus acciones y discursos en el contexto de producción (lo que en este artículo es considerado como la dimensión simbólica de lo social).

Para la realización de la investigación se consideraron de los relatos de vida de inmigrantes chilotes que actualmente residen en la ciudad de Punta Arenas y que provenían de algún punto geográfico de Chiloé, en el período comprendido hasta 1980, ya que en las siguientes décadas esta migración descendió fuertemente, debido a las causas mencionadas previamente. 
Las entrevistas se realizaron en dos fases durante el año 2014: la primera, durante marzo de dicho año; y la segunda, en julio del mismo período. En total, se entrevistó a 15 inmigrantes chilotes, de los cuales se seleccionaron ocho casos, debido a la extensión de los relatos de vida y la especificidad de las trayectorias que estos sujetos entregaron, siguiendo los criterios del análisis de contenido y la saturación de información (Andréu, 2001).

\section{Marco conceptual}

La estrategia de análisis se realizó por medio del análisis de contenido. Este análisis gira en torno a la información recopilada en los relatos de vida de las/los inmigrantes chilotes y, por lo tanto, toma el objetivo de conocer y describir el proceso social de esta migración. Dicho análisis se define por medio de procedimientos sistemáticos y objetivos, permitiendo la interpretación de los sentidos latentes expresados en un texto, moviéndose por tres niveles de análisis: sintáctico (lo que se dice), semántico (cómo se dice) y pragmático (lo que se construye con el habla) (Navarro y Díaz, 1998). Para el caso específico de los relatos de vida, estos pueden ser analizados por su interés como contenido en sí, como lo que se puede inferir y en el contexto en el que se enmarcan.

En concreto, se desarrolló un esquema con dimensiones que responden directamente a los objetivos de la investigación, donde posteriormente se extrajeron los tópicos a partir de los conceptos desarrollados en el marco teórico. Ahora bien, en la presentación de los resultados para este artículo se profundizará en la dimensión simbólica de los discursos de las/los entrevistados. ¿Qué significa ser un inmigrante nacional? ¿Cómo se define? Para intentar responder a estas preguntas se analizarán los conceptos de extranjero desde Simmel (1939) y Schütz (1974) y de estigma desde Goffman (2006).

Primero, cabe establecer algunos conceptos desarrollados por Simmel (1988) para el análisis de la interacción social. Este autor configura la interacción sobre la base de dos elementos: el contenido y las formas; donde el contenido refiere a los impulsos, propósitos e intereses del individuo (Simmel, 1988); mientras que la forma es el principio básico que estructura todo ese contenido, es decir, como se socializa constreñidos por formas de interacción estabilizadas en el tiempo, esto es, un modo de ser esperado para un espacio social delimitado. 
Dado que el interés de esta investigación es analizar relatos de vida de inmigrantes, se debe situar la vivencia del extranjero en su llegada al nuevo grupo social, puesto que el individuo está inmerso en un mundo que no le es privado, sino que es social (Salas, 2006). Schütz (1974) aborda el mundo de la vida cotidiana y la pauta cultural del grupo al que el forastero migra. La expresión pauta cultural de la vida grupal la define como: "todas las valoraciones, instituciones y sistemas de orientación y guía peculiares (tales como usos y costumbres, leyes, hábitos, etiqueta y modas) que (...) caracterizan a todo grupo social en un momento determinado de su historia" (Schütz, 1974, p. 96). Toda persona que haya nacido o formado dentro del grupo aceptará un esquema que guía las situaciones que se dan. Esta certeza no es tal para el forastero, debido a que no tiene autoridad en dicho esquema y desde la perspectiva del grupo normal "él es un hombre sin historia" (Schütz, 1974, p. 100). Esta pauta cultural para el forastero no será un refugio ni algo propio, sino un campo de aventura y una situación problemática en sí misma (Schütz, 1974).

Por lo tanto, es ineludible comprender la situación del inmigrante de acuerdo con valores límites de inclusión o exclusión en un grupo social. La sociología de Goffman habilita entender este proceso por medio del concepto de estigma y su análisis de la interacción social.

Complementariamente, el término estigma goffmaniano es utilizado para dar cuenta de un atributo que marca fuertemente a un sujeto. Según los atributos de las personas, estas los categorizan como normales o estigmatizados. A primera vista, esto se observa en la apariencia del individuo, lo que denomina identidad social virtual, mientras que las categorías y atributos pertenecientes al sujeto conforman su identidad social real (Goffman, 2006). Al presentarse un atributo que vuelve a la persona diferente de las demás, este es observado como un estigma. Se distinguen tres tipos de estigma: las abominaciones del cuerpo, los defectos de carácter del individuo y los estigmas tribales de raza, nación o religión (que pueden ser transmitidos por herencia) (Goffman, 2006). Así, las/los normales adoptan ciertas actitudes y conductas hacia las/los estigmatizados - valiéndose del supuesto de que dicha persona no es completamente humana-: practican varias formas de discriminación e intentan explicar su inferioridad y lo peligroso que puede suponer el sujeto con estigma (Goffman, 2006). 
Estas conductas estarían mediadas por la interacción entre los sujetos, "como la influencia recíproca de un individuo sobre las acciones del otro cuando se encuentran ambos en presencia física inmediata" (Goffman, 2009, p. 27). Lo que el autor denomina situación social mixta, que refiere a un control recíproco del ambiente donde ocurre. En este espacio de interacción se comprende que todo individuo posee ciertas características sociales, teniendo cierto derecho moral de esperar que otros lo traten de una forma apropiada (Goffman, 2009). En este punto la/el estigmatizado disrumpe en tanto es un individuo que no posee esas características sociales y que, por lo tanto, no puede esperar dicho trato de las/los otros. La interacción se encuentra organizada según líneas de adaptación, donde el sujeto se adecúa a qué es lo que quiere ser y qué no haría para lograr sus fines, y en la medida que está dispuesto a someterse al control social informal podrá utilizar todas las herramientas para enfrentar dicho momento, ya que para protegerse solo necesita tener cuidado con los juicios que expresa (Goffman, 1970). En ese aspecto, la/el estigmatizado responde muchas veces corrigiendo directamente lo que considera como cimiento de su estigma, lo que no implica que el individuo cambie a un estatus normal, sino que transforma su yo para la necesidad de pertenecer a tal grupo social normal (Goffman, 2006).

Goffman (2006) conceptualiza la identidad personal que se caracteriza por ser única, entendida a través de los soportes de identidad y la combinación de hechos de una persona. La identidad personal se relaciona "con el supuesto de que el individuo puede diferenciarse de todos los demás, y que alrededor de este medio de diferenciación se adhieren y entrelazan (...) los hechos sociales de una única historia continua" (Goffman, 2006, p. 73). En ese sentido, el individuo intentará demostrar su identidad para tal caso o en un caso contrario intentará esconderla, en la medida en que este yo proyectado es amenazado, pudiendo indignarse, pero detrás del yo existe un principio mayor: el organizativo, por lo que en ciertos momentos el individuo puede sacrificarse, pero los principios básicos se verán mantenidos (Goffman, 1970). A partir de esto, es posible apreciar al individuo como entidad de la cual es posible construir una historia y como objeto de biografía (Goffman, 2006). 
Relacionando el concepto del estigma con este estudio, será necesario comprender al inmigrante como poseedor de dicho atributo que lo diferencia entre chilotes y no chilotes en Magallanes. Cómo fue históricamente construido la/el chilote como otro en Magallanes excede al propósito de este artículo, pero sí se abordarán las múltiples manifestaciones (Wieviorka, 1994) que este proceso presenta.

\section{Presentación de resultados}

A continuación, se presentarán una descripción de los procesos de diferenciación social de las/los chilotes en Magallanes descritos a propósito de las principales citas de los corpus transcritos de sus discursos.

La principal característica de la dimensión simbólica del discurso de las/los chilotes es que presenta una ambivalencia entre el estigma de ser chilote y la identidad trabajadora, pero además con la tensión de mantener las costumbres típicas de la isla. Esto a su vez presentará diferencias entre el grupo asociado a la clase media-alta y el proveniente de una clase baja campesina, en relación con las formas de socialización y cómo se estructuran los impulsos e intereses individuales (Simmel, 1988).

Porque donde hay un chilote, sale adelante ... ¿Por qué buscan a los chilotes para trabajar? Porque son trabajadores, ¿y qué más le pueden sacar a un chilote? ¿Por qué estudiaron un poco más y uno no sabe defenderse? (Entrevistada 3, llegada en 1954).

Porque aquí empezaron a conocer que el chilote era trabajador, el chilote no sería una persona preparada, diríamos, técnicamente, profesionalmente, pero sabía de todo [...] veían que no levantaba cabeza cuando trabaja. (Entrevistada 8, llegada en 1945).

En general, las/los entrevistados no reconocen situaciones de discriminación cuando se les pregunta directamente y más bien las asocian a un período de tiempo anterior, ya que dejan entrever que en la actualidad estas no existen. No obstante, a medida que se avanza en la conversación, relatan las formas de respuesta a situaciones discriminatorias y la percepción negativa que tendrían las/los magallánicos e inmigrantes extranjeros sobre las/los chilotes. Así, la/el chilote emerge como una figura marginal que permite delimitar lo normal (Simmel, 1939), ya que la/el migrante es quien llega desde fuera y enfrenta una 
pauta cultural nueva, donde debe aventurarse y aprender cómo moverse (Schütz, 1974). Es decir, se configurará como un otro que, por lo tanto, será objeto de construcción de estereotipos que producen prejuicios en la sociedad.

Hay mucha gente de Chiloé, que son Cárdenas, Alvarado, estos apellidos no llegan a grandes cargos, y tú lo vas a ver en todas esferas, que llegan hasta cierto punto. ¿Políticos habrá muchos? No. Yo creo que en las políticas de Estado que se aplican no se incluyen. (Entrevistada 5, llegada en 1976).

El caso mío no, porque es también como uno se va desplantando, yo no puedo mirar en menos a nadie. Entonces si usted respeta, va a ser respetado, yo he jamás he tenido un problema acá, con nadie. (Entrevistado 6, llegado en 1963).

No he tenido esa experiencia [de discriminación], siempre he tenido buenos roces con gente, nosotros somos muy reacios, mira, es que pasando los hijos, no somos de salir, eso es lo que pasa. (Entrevistada 7 , llegada en 1967).

El hecho de ser chilote se muestra como una causa de discriminación en situaciones sociales, que en clave goffmaniana se define como un estigma de raza ${ }^{13}$ (Goffman, 2006), intersectando en este caso con aspectos culturales y de clase que se establecen como una indeseable diferencia y que se traducen en desacreditación del sujeto. Este reconocimiento interfiere en las interacciones cotidianas y produce una situación de turbación del curso normal de estas (Goffman, 2006).

Eran mal vistos (...) vistos como ignorantes y que hacían el trabajo más sucio, el más bajo (...) hasta los mismos hijos de chilotes que ya tenían una mejor situación miraban en menos a los que estaban recién llegando. (Entrevistada 1, llegada en 1961).

Asustada, admirada, media huasita (...) siempre fui de conversar y yo decía, si en algo me equivoco corrígeme, porque yo vengo recién

13 Si bien como ya indica la ONU, las razas no existen, pero sí persiste el racismo como sistema, ideología y prácticas (Campos, 2017). A lo que se refiere Goffman es a la marca de origen que presentan las consideraciones manifestadas en la etnia, color de piel, nacionalidad o territorialidades, tal como se utiliza en el presente artículo. 
de Chiloé, pero yo primero observaba, no fui tan tontita, porque yo observaba. (Entrevistada 7, llegada en 1962).

La ignorancia o lo que podría entenderse como sinónimo de ser huaso, bruto o retraído, es una de las características principales que se asocia con el chilote, tanto en el sentido social (de poseer escasas habilidades de comunicación) como intelectual o educacional, lo que indudablemente alude a una dicotomía entre barbarie/civilización. Esto se visibiliza en el estigma que cargarían como individuos manchados o carentes de hábitos que precisa el civismo. El acento y la forma de hablar se constituyen como signos que permiten el reconocimiento como chilotes y que evidencian aún más su subdesarrollo cultural.

Porque aquí como hubo tanta mezcla de gente extranjera, la gente aprendió a ser limpia, porque mucha gente de Chiloé venía del campo, no sabían de agua potable ni luz, la gente que venía a trabajar a las estancias venía de los campos de Chiloé, apenas sabían leer y escribir. (Entrevistada 8, llegada en 1945).

La otra característica del estigma chilote es lo referido a la clase social. En primer lugar, como un estereotipo de pobreza, fomentado por el origen predominantemente rural de las/los migrantes. Y, en segundo lugar, por su posición en la estructura laboral, en nichos de trabajos manuales de baja calificación, como consecuencia de su carácter de ignorantes. En resumen, producto de su origen rural serían ignorantes y pobres económicamente, condiciones que solo les permitirá acceder a trabajos precarios y de alto esfuerzo físico.

Vinimos medios huasos, pero uno se empieza a relacionar y cambia. (Entrevistado 4, llegado en 1957).

Todos trabajaban en las estancias, de carreteros, de ovejeros, de esquiladores, de jardineros, todos eran gente de Chiloé que venían así, sin nada, y se presentaban a las oficinas grandes de los estancieros aquí ...venían poco tiempo y la gente era media retraída, no diría ignorante, porque la gente con la cultura que se va repartiendo aprenden. (Entrevistada 8, llegada en 1945).

En el caso de las mujeres que migraron, estas condiciones se agudizan, puesto que el principal nicho laboral era como empleadas puertas adentro, lo que se asemeja al caso de las nanas peruanas, que Correa 
(2011) explica como la ausencia de vida propia, independiente y autónoma, ya que pasan a depender de la familia empleadora.

Había mucha gente en el muelle esperando a las personas que venían a trabajar (...) se iban a pelear las empleadas domésticas. (Entrevistada 1, llegada en 1961).

Las empleadas me las mandaban de Castro, le pedía empleada doméstica y me la mandaban. Así que, ellas pagaban su pasaje de a poquito, le iba descontando de a poquito, porque no había pa' pagarle el pasaje, mi hermana le compraba el pasaje allá. (Entrevistada 8, llegada en 1945).

Concretamente, esta discriminación negada por las/los propios chilotes, se refleja en un aspecto propio de la pauta cultural puntarenense, puesto que la persona que cumpliera con alguna de estas características o simplemente se le quisiera desacreditar, se le tilda de ¡chilote! Por lo que se resignifica el pertenecer a Chiloé, derechamente estigmatizando esta condición y pasa a ser motivo de burla y vergüenza.

Porque los yugoeslavos fueron los inmigrantes más jodidos que llegaron acá (...) te digo que eran muy discriminadores. Pero hoy día no se ve tanto, antes sí, el chilote era muy mal mirado y siempre como insulto: ¡Este chilote! (Entrevistada 3, llegada en 1954).

Yo no noté diferencias, pero notaba que cuando alguien se enojaba le decían: ¡Chilote! Como una ofensa, sin entender, como decirte yo chileno, es como decirte puntarenense (...) cuando se peleaban: Ah, te vas a casar con un chilote (...) usaban el término chilote como un adjetivo despectivo. (Entrevistada 8, llegada en 1945).

Las personas que han enfrentado algún tipo de estigma atraviesan por aprendizajes acerca de la pauta cultural a la que se enfrentan y en relación con su condición. Uno de los aprendizajes pasa por las formas en que se responde a las situaciones de discriminación, y que dentro de este artículo es uno de los elementos que diferencia internamente a las/los chilotes. La actuación en estas situaciones muchas veces se transforma en una rutina - como plantea Goffman (2009) - ya probada: negar el lugar de procedencia y cambiarlo por un lugar más desarrollado dentro o fuera de la isla, lo que dará cuenta de un modo de adaptación para poder pertenecer al grupo social normal. 
Otra forma de réplica es avergonzarse frente al descrédito de las/los puntarenenses - que muchas veces deriva en negación-, cuando intentan demostrar que su diferencia carece de importancia para entablar una relación social completa. La respuesta del grupo asociado a una clase media instruida difiere de las anteriores, ya que se plantea una confrontación frente a situaciones conflictivas por ser chilotes - por ejemplo, interpelando a quién lo discrimina-, dando cuenta de una forma de socialización distinta frente a un mismo impulso de vergüenza.

Yo soy chilota y siempre los he defendido (...) eso también hace que el mismo chilote cuando se le pregunta de dónde es, dice: Soy de Puerto Montt, soy de Osorno, soy de Valdivia (...) porque se sienten discriminados (...) no es que renieguen, para no sentir en ese momento lo que va a decir el otro. (Entrevistada 1, llegada en 1961).

Porque había chilotes que no querían ser chilotes, tenían vergüenza de serlo, porque antes se reían mucho por su manera de hablar (...) ellos decían que eran de Puerto Montt. (Entrevistada 3, llegada en 1954).

La forma de evadir, hacer frente al estigma del chilote y asimilarse a la sociedad magallánica es por medio del valor del trabajo como forma última de socialización. A partir del impulso de búsqueda de mejores condiciones económicas, las/los entrevistados apuntan a que la/ el chilote se caracteriza por ser trabajador, lo que a su vez implica otros valores positivos como la responsabilidad y el compromiso. Esta característica permite disminuir la carga negativa que se les asocia, así como es la principal forma de integración a la comunidad.

Y el chilote es muy pata de perro, lo vas a encontrar desde acá hasta Arica (...) Acá primero llegó el chilote, después vino el croata, vino el italiano. (Entrevistado 2, llegado en 1965).

El chilote es trabajador, bastante responsable, es muy reconocido pa'l trabajo de campo, duro, duro, duro. (Entrevistado 4, llegado en 1957).

La característica que tenemos los chilotes es que somos muy trabajadores. Entonces, yo creo que la gente que venía de Chiloé siempre fue subordinada a ellos [los yugoslavos] (...) quizás vaya más por eso, ¿será discriminación? ¿Será que no sabían hacer otras cosas? (Entrevistada 5, llegada en 1976.) 
Por otro lado, la identidad chilota es un aspecto que genera un sentimiento de orgullo en todos las/los entrevistados.

Siempre haciendo las comidas de allá, tratando de hacer todas las comiditas de allá: la mazamorra de manzana, las cazuelas y conservando su modo de hablar, sobre todo, que eso no lo dejaron nunca. (Entrevistada 1, llegada en 1961).

La verdad de que acá hay un sentimiento de los chilotes, no nos olvidamos que por un grupo de chilotes somos chilenos, estamos donde estamos y acá no hubo ni violencia ni armamento, hubo inteligencia, coraje y valor. (Entrevistado 2, llegado en 1965).

Nunca me avergoncé de ser chilota, las cosas que me decían les sabía parar en seco, porque empecé a educarme acá (...) participando en las directivas de los colegios tuve otro roce, fui aprendiendo a defenderme. (Entrevistada 3, llegada en 1954).

Esto se refleja en sus distintas prácticas y mantención de las costumbres propias de la cultura isleña y que llevan a cabo tanto en el espacio privado como público. Las principales tradiciones refieren a la comida, la celebración de algunas fiestas típicas y —como algunos de las/los entrevistados relatan-con la forma de hablar del chilote, ya que se va conformando un léxico propio en su lenguaje, con gran cantidad de modismos y adaptaciones del español antiguo. Sin embargo, en la actualidad existiría una crisis identitaria, debido a que por el paso de las generaciones y la adaptación a la cultura en Magallanes, se habrían perdido muchas tradiciones y particularmente la lengua. El sentimiento de orgullo por sus raíces da cuenta de una ambivalencia del discurso, puesto que características asociadas a la barbarie y subdesarrollo de la ignorancia del chilote son motivo de orgullo para la mantención de la propia cultura.

Este último elemento inevitablemente se asocia con la producción de organizaciones sociales que tengan como misión conservar estas tradiciones, que permitirían adaptar e integrar a las/los chilotes en la sociedad puntarenense, como bien se expresa en las siguientes citas.

Un día una amiga me dice: ¿tú por qué no vas al Centro de Hijos de Chiloé? (...) Y ahí fui, había un localcito chiquitito, había dos mesitas (...) había una directiva ya formada y me invitaron a esa reunión. (Entrevistada 3, llegada en 1954). 
Nos juntamos un grupo de gente y formamos esto, yo soy uno de los socios más antiguos, yo fui presidente varios años (...) llegamos nosotros a tener 300 socios inscritos, hoy día habimos (sic) 47. (Entrevistado 4, llegado en 1957).

Después de casado estuve metido en un grupo folklórico, donde hacíamos música de Chiloé, yo tocaba la guitarra y cantaba, estuve 5 años. (Entrevistado 6, llegado en 1963).

Donde se observa que esto se genera a partir de redes de amistades (o redes familiares en otros casos). Además, se manifiesta el cambio generacional desde los/las chilotas que establecieron estas organizaciones, a la actualidad donde se observa una pérdida de interés por pertenecer a estas, de quienes tienen ascendencia chilota o de nuevos migrantes llegados a la región en las últimas décadas.

\section{Conclusiones}

Los principales resultados presentados en este artículo complementan los antecedentes observados en investigaciones anteriores: en Magallanes existe una importante presencia de elementos culturales y simbólicos de la inmigración chilota que ha generado procesos de diferenciación social en términos de ruptura y continuidades con las tradiciones de la sociedad de origen en la sociedad de llegada.

Los significados que adquieren las relaciones sociales desarrolladas por las/los inmigrantes en Magallanes tienen directa relación con una ética ${ }^{14}$ de superación y de posibilidad de crecimiento económico y social, actuando como principal mecanismo de salida hacia una realidad adversa presente en Chiloé, tal como también indicó la investigación de Riveros Quinteros y Fernández Génova (2018). En ese sentido, el valor del chilote trabajador adquiere principal importancia como elemento diferenciador y potenciador de oportunidades en la sociedad puntarenense, cuyo significado fue la forma de hacer frente a los prejuicios y estereotipo del chilote como ignorante, cuestión que refuerza la construcción de otredades y su impacto en las identidades en conflicto, cuestión documentada en la teoría goffmaniana y en las

14 Utilizado, al igual que Weber en la Ética Protestante y el Espíritu del Capitalismo como modo de vida. 
investigaciones de Saldívar $(2017 ; 2018 ; 2019)$ y profundizadas en este estudio. Este impulso por intentar salir adelante y establecerse económicamente, generó una invisibilización de las/los chilotes como grupo social con identidad y con capacidad de organización, lo que se refleja por ejemplo en el tiempo que demoraron en formar sus organizaciones sociales.

Se obvia la característica de inmigrante nacional, ya que igualmente la/el chilote pasa a ser un desacreditado, debido a que no cumple con los cánones de la constitución del estado nacional y del estado regional, en este caso (que se atribuye al extranjero yugoslavo). Dicho aspecto, en el análisis de los relatos de vida, se demostró a partir de la autopercepción de las/los chilotes, donde se asumen como sujetos estigmatizados, lo que igualmente no lo reflejan en situaciones sociales concretas, lo que es un paralelo también con lo que ocurre con migrantes internacionales en el actual patrón migratorio donde se autoidentifican discriminados (Aravena y Alt, 2012). Un aspecto por destacar es que la mayoría de las/los entrevistados no admite eventos de discriminación, pero en la medida que la temática emerge en la conversación intentan dar una explicación a aquello y relatan las formas de enfrentar situaciones de ese tipo. Por ejemplo, con la resignifcación de la palabra chilote o con chilotear $^{15}$ a una persona, ya que al ser utilizada en cierta manera - con una entonación y tono particular- es un insulto y motivo de burla, lo que se enfrenta con el orgullo de ser chilote, produciendo que los y las migrantes busquen con más ahínco deshacerse de este estigma por medio del trabajo - y el ser trabajadores-. Esto, logra constatar que el estigma de raza y de clase estuvo presente en la cotidianeidad de los individuos, sin embargo, esto no es comprobable en la actualidad.

Particularmente, la figura del yugoslavo ${ }^{16}$ en algunos relatos emerge como tipo ideal de trabajador y colonizador de Magallanes, hecho que refuerza las distinciones y diferencias entre las/los chilotes y las/los normales, que pueden ser otros inmigrantes no chilenos o las/los pun-

15 Tratar de chilote a otra persona.

16 Se habla de yugoslavo en vez de otras nacionalidades de dicha región europea, debido a que la mayor parte de inmigrantes que llegó de la península balcánica a Magallanes lo hizo previamente a la disolución de Yugoslavia en 1991, y dicho apelativo se mantiene - en muchas ocasiones también se habla del croata— hasta la actualidad. 
tarenenses ${ }^{17}$. Esto permitirá constituir una ambivalencia entre un ellos/ as y un nosotros/as, que Simmel (1939) advierte como la existencia de una frontera interna de exclusión a la sociedad. La ambivalencia coincide con las categorías de estigmatizados (como nosotros/as) y normales (como ellos/as) y que a su vez es coherente con el resumen de las características asociadas a cada grupo que recopila Ortega Perrier (1980). Por ejemplo, las/los chilotes se asumen como ignorantes mientras que las/ los yugoslavos estarían culturalmente desarrollados; ellos/as son limpios/as, nosotros tuvimos que aprender a serlo; entre muchas otras características que se vinculan con la vergüenza y que legitiman el estigma.

En ese sentido, las relaciones sociales adquiridas por las/los chilotes se significan por medio del trabajo, presentándose como el principal mecanismo de integración social y forma de socialización en la sociedad magallánica, ya que por valores como esfuerzo y responsabilidad logran cumplir sus fines personales y familiares, y asimismo hacer frente al estigma de ser chilotes.

Es interesante dar cuenta de cómo las manifestaciones de las diferencias que se realizan en Magallanes no son siempre explícitas. Como fue posible evidenciar, los y las entrevistadas no indican prácticas discriminatorias explícitas, pero sí configuran a través de los discursos cuáles son los espacios - físicos y simbólicos- de exclusión. Esta es, en concreto, una de las dimensiones sociológicas más relevantes que la estrategia de análisis cualitativo de contenido pretende informar: lo latente frente a lo manifiesto.

De tal modo, se puede observar el aspecto sustantivo de la teoría goffmaniana del estigma: la configuración de una estructura social diferenciada. El estigma no es solo lo que se le imputa como negado al cuerpo, cultura o trayectoria del otro, sino un marcador que diferencia las trayectorias de las personas, ya sea habilitándolas o constriñéndolas, lo que ocurre con la población chilota en Punta Arenas que se ve racializada (Tijoux y Palominos, 2015) y condicionada a ciertas

17 Existe una dificultad para establecer claramente qué significa ser puntarense o quiénes eran las/los puntarenses - en el período que relatan sus trayectorias de vida los y las entrevistadas-, ya que su identidad está intrínsecamente relacionada con Chiloé, por lo que no queda establecido qué los diferencia de las/los chilotes. De todos modos, dicha definición se escapa del objetivo de este artículo y es otro elemento que se agrega al debate acerca de la historia e identidad magallánica. 
trayectorias precarizadas frente a las/los no chilotes. Las imágenes y prejuicios, junto con su asociación normalizada de elementos morales depreciados a la condición migratoria chilota constituye hasta el día de hoy una forma social — como diría Simmel (1988) — a partir de interacciones estables y duraderas en el tiempo, que se institucionalizan en una socialización que marca las guías de comportamientos y de relaciones entre sujetos y grupos.

\section{Referencias}

Aguilar, R., Ortiz, F., y Valdés, P. (2012). La tradición del rito fúnebre de la isla de Chiloé en Punta Arenas: un aporte a la construcción de la cultura magallánica (Tesis de pregrado). Universidad de Magallanes, Punta Arenas, Chile. Recuperado de http:// www.bibliotecadigital.umag.cl/handle/20.500.11893/208

Andréu, J. (2001). Las técnicas de análisis de contenido: una revisión actualizada. Revista Fundación Centro Estudios Andaluces, 10(2), 1-34. Recuperado de https://perio.unlp.edu.ar/ tesis/sites/perio.unlp.edu.ar.tesis/files/S200103-Las\%20 t\%C3\%A9cnicas\%20de\%20An\%C3\%Allisis\%20de\%20Contenido\%20-\%20Una\%20revisi\%C3\%B3n\%20actualizada.pdf

Aravena, A. y Alt, C. (2012). Juventud, migración y discriminación en el Chile contemporáneo. Última Década, 20(36), 127-140. https://doi.org/10.4067/s0718-22362012000100006

Archer, M. (2009). Teoría social realista. Santiago de Chile: Ediciones Universidad Alberto Hurtado.

Bertaux, D. (1980). El enfoque biográfico: su validez metodológica, sus potencialidades. Proposiciones, 29, 1-22.

Calderón, F., Hopenhayn, M., y Ottone, E. (1996). Esa esquiva modernidad. Desarrollo, ciudadanía y cultura en América Latina y el Caribe. Caracas: Editorial Nueva Sociedad.

Camas, V. (2001). Olvido y vigencia del campesino polaco en Europa y América. Revista Empiria, 4, 211-240. https://doi. org/10.5944/empiria.4.2001.885

Campos, L. (2017). Racismo em três dimensões: Uma abordagem realista-crítica. Revista Brasileira de Ciências Sociais, 32(95), 2-19. https://doi.org/10.17666/329507/2017

Cano, V. y Soffia, M. (2009). Los estudios sobre migración internacional en Chile: apuntes y comentarios para una agenda de inves- 
tigación actualizada. Revista Papeles de Población, 15(61). 129-167. Recuperado de http://www.scielo.org.mx/scielo. php?script=sci_arttext\&pid=S1405-74252009000300007\&lng $=$ es\&tlng=es

Comisión Económica para América Latina y el Caribe, CEPAL. (2020). Migración Interna. Santiago de Chile: Comisión Económica para América Latina y el Caribe, CEPAL. Recuperado de https://www.cepal.org/es/temas/migracion-interna

Correa, J. (2011). Ser inmigrante en Chile. La experiencia de racismo cotidiano de peruanos y peruanas en la ciudad de Santiago (Tesis de pregrado). Universidad de Chile, Santiago de Chile. Recuperado de http://repositorio.uchile.cl/handle/2250/130580

Gadea, C. A. (2018). El interaccionismo simbólico y sus vínculos con los estudios sobre cultura y poder en la contemporaneidad. Sociológica, 33(95), 39-64. Recuperado de http://www. scielo.org.mx/scielo.php?script=sci_arttext\&pid=S018701732018000300039\&lng=es\&tlng=es

Goffman, E. (2006). Estigma. La identidad deteriorada. Buenos Aires: Amorrortu Editores.

Goffman, E. (1970). Ritual de la interacción. Buenos Aires: Editorial Tiempo Contemporáneo.

Goffman, E. (2009). La presentación de la persona en la vida cotidiana. Buenos Aires: Amorrortu Editores.

Gómez, S., Arteaga, J., y Cruz, M. E. (1981). Cambios estructurales en el campo y migraciones en Chile: estudios de casos. Tomo I. Documento de trabajo $\mathrm{N}^{\circ} 128$. Santiago de Chile: Facultad Latinoamericana de Ciencias Sociales, FLACSO.

Harambour, A. (2009). Racialización desde afuera, etnización hacia dentro. Clase y región en el movimiento obrero de la Patagonia, principios del siglo XX. En F. Gaune y M. Lara (Eds.), Historias de racismo y discriminación en Chile (pp. 369-394). Santiago de Chile: Uqbar Editores.

Instituto Nacional de Estadísticas, INE y Departamento de Extranjería y Migración, DEM. (2019). Estimación de personas extranjeras en Chile al 31 de diciembre 2018. Recuperado de https:// www.extranjeria.gob.cl/media/2019/07/Estimación-Población-Extranjera-en-Chile.pdf

Jorquera, J. (2016). De Chiloé a Magallanes: relatos de vida de inmigrantes chilotes. (Tesis de pregrado). Universidad de Chile, 
Santiago de Chile. Recuperado de http://repositorio.uchile. $\mathrm{cl} /$ handle/2250/151042

Lausic, S. (2005). Migraciones del archipiélago de la isla grande de Chiloé hacia la Patagonia (Chile-Argentina) y participación en el sindicalismo obrero. Santiago de Chile: Archivo Chile, Centro de Estudios “Miguel Enríquez", CEME.

León, M. A. (2015). Una provincia "enteramente insular": geografía, exploraciones y cotidianeidad en Chiloé republicano, Chile (1826-1900). Magallania, 43(1), 53-68. https://dx.doi. org/10.4067/S0718-22442015000100004

Mancilla, C. y Rehbein, R. (2009). Comunicación y representación migraciones. Sobre la producción e institucionalización del imaginario de la vida errante en los procesos de transmisión cultural: El caso de Chiloé en la primera mitad del siglo XX. Revista F@ro-Monográfico, 9, 1-9. Recuperado de http:// web.upla.cl/revistafaro/n09/pdf/art04.pdf

Mansilla Contreras, J. (2012). Chilotes en la Patagonia. Recuperado de https://territoriosdefrontera.wordpress.com/2012/08/14/ chilotes-en-la-patagonia-por-jose-mansilla-contreras-magister-en-antropologia-y-desarrollo-universidad-de-chile/

Margulis, M. (1997). Cultura y discriminación social en la época de la globalización. Revista Nueva Sociedad, 152, 37-51. Recuperado de https://nuso.org/articulo/cultura-y-discriminacion-social-en-la-epoca-de-la-globalizacion/

Margulis, M. y Urresti, M. (1999). La segregación negada. Cultura y discriminación social. Buenos Aires: Editorial Biblos.

Martínez Pizarro, J. (1994). Dinámica de la población de Chile: Notas sobre el proceso de redistribución espacial. Santiago de Chile: Centro Latinoamericano y Caribeño de Demografía, CELADE.

Martinic, M. (1988). Magallanes 1921-1952: Inquietud y crisis. Punta Arenas: La Prensa Austral.

Martinic, M. (1992). Historia de la Región Magallánica (Vol. 1). Punta Arenas: Universidad de Magallanes.

Martinic, M. (1999). La inmigración chilota en Magallanes. Apreciaciones sobre sus causas, características y consecuencias. Anales del Instituto de la Patagonia, 27, 27-47. Recuperado de http:// www.bibliotecadigital.umag.cl/handle/20.500.11893/1341 
Martinic, M. (2002). Breve historia de Magallanes. Punta Arenas: Universidad de Magallanes.

Mills, C. (1986). La imaginación sociológica. México, D.F.: Fondo de Cultura Económica.

Montiel, D. (2007). El influjo de los chilotes en la Patagonia. Santiago de Chile: Editorial Poetas Antiimperialistas de América.

Muñoz Rau, J. y Zamora Mondaca, E. (1975). El inmigrante chilote en la Patagonia magallánica (Tesis de pregrado). Universidad de Valparaíso, Valparaíso.

Navarro, P. y Díaz, C. (1998). Análisis de contenido. En J. Delgado y M. Gutiérrez (Eds.), Métodos y técnicas cualitativas de investigación en ciencias sociales (pp. 177-224). Madrid: Síntesis.

Ortega Perrier, M. (1980). Chiloé en Magallanes: familias inmigrantes en Punta Arenas (Tesis de pregrado). Universidad de Chile, Santiago de Chile.

Raczynski, D. y Vergara, P. (1978). Migración interna en Chile: características y tendencias en las últimas décadas. Documentos de trabajo No13. Santiago de Chile: CIEPLAN.

Riveros Quinteros, K. y Fernández Génova, M. (2018). Chiloé en otro lugar. Memorias de migraciones a Punta Arenas. Revista Sophia Austral, 22, 137-161. https://dx.doi.org/10.4067/S071956052018000200137

Rodríguez Uribe, M. (2006). Historia del trabajo en Magallanes y la Patagonia: la última década del siglo XIX. Santiago de Chile: Archivo Chile, Centro de Estudios “Miguel Enríquez", CEME.

Rodríguez Vignoli, J. (2019). Migraciones internas en Chile, 1977-2017: continuidad y cambio. Serie Población y Desarrollo $\mathrm{N}^{\circ} 126$. Santiago de Chile: Comisión Económica para América Latina y el Caribe, CEPAL.

Salas. R. (2006). El mundo de la vida y la fenomenología sociológica de Schütz. Hermenéutica intercultural: Revista de Filosofía, 15, 167-199. Recuperado de http://biblioteca-digital.ucsh.cl/ greenstone/collect/revistal_old/index/assoc/HASH135c. dir/El\%20mundo\%20de\%20la\%20vida.pdf

Saldívar, J. M. (2017). “Chilote tenía que ser”: Vida migrante transnacional en territorios patagónicos de Chile y Argentina. Cultura-hombre-sociedad, 27(2), 175-200. https://dx.doi. org/10.7770/cuhso-v27n2-art1221 
Saldívar, J. M. (2018). Etnografía de la nostalgia: migración transnacional de comunidades chilotas en Punta Arenas (Chile) y Río Gallegos (Argentina). Chungará, 50(3), 501-512. https:// dx.doi.org/10.4067/S0717-73562018005001201

Saldívar, J. M. (2019). Religión vivida, migración y transnacionalismo. El caso del Nazareno de Caguach en Punta Arenas, Chile, y Río Gallegos, Argentina. Migraciones Internacionales, 10, e2184. https://doi.org/10.33679/rmi.vli1.2184

Saldívar, J. M. y Terrado, L. (2019). Os "Viajeros Golondrina": uma etnografia transnacional da migração chilota em Fuego-Patagônia do Chile e Argentina. Mana, 25(1), 126-158. https:// doi.org/10.1590/1678-49442019v25nlp126

Schütz, A. (1974). El forastero. Ensayo de psicología social. En A. Schütz (Ed.), Estudios sobre teoría social (pp. 95-107). Buenos Aires: Amorrortu Editores.

Simmel, G. (1939). Digresión sobre el extranjero. En G. Simmel (Ed.), Estudios sobre formas de socialización (pp. 273-296). Buenos Aires: Espasa-Calpe.

Simmel, G. (1988). Cuestiones fundamentales de sociología. Barcelona: Editorial Gedisa.

Singer, P. (1988). A modo de introducción. Urbanización y clases sociales. En M. Bassols, R. Donoso, A. Massolo y A. Méndez (Eds.), Antología de sociología urbana (pp. 27-44). México, D.F.: Universidad Nacional Autónoma de México, UNAM.

Singer, P. (2003). Migraciones internas: consideraciones teóricas sobre su estudio. Revista Derechos Humanos, Órgano Informativo de la Comisión de Derechos Humanos del Estado de México, 62, 51-67.

Thomas, W. y Znaniecki, F. (2006). El campesino polaco en Europa y en América. Madrid: Centro de Investigaciones Sociológicas y Boletín Oficial del Estado. Trabajo original publicado en 1920.

Tijoux, M. E. (2014). El otro inmigrante "negro" y el Nosotros chileno. Un lazo cotidiano pleno de significaciones. Boletín Onteaiken, 17, 1-15. Recuperado de http://onteaiken.com.ar/ ver/boletin17/art-tijoux.pdf

Tijoux, M. E. y Palominos, S. (2015). Aproximaciones teóricas para el estudio de procesos de racialización y sexualización en los fenómenos migratorios de Chile. Polis, Revista Latinoame- 
ricana, 14(42), 247-275. https://dx.doi.org/10.4067/S071865682015000300012

Urbina, R. (1988). Chiloé, foco de migraciones. En Instituto de Investigaciones del Patrimonio Territorial de Chile, USACH (Ed.), Chiloé y su influjo en la XI Región. II Jornadas Territoriales (pp. 31- 46). Santiago de Chile: Editorial Universitaria.

Urbina, R. (2002). La vida de Chiloé en los tiempos del fogón, 1900-1940. Valparaíso: Editorial Universidad de Playa Ancha.

Urbina C., X. (2013). Expediciones a las costas de la Patagonia Occidental en el período colonial. Magallania, 41(2), 51-84. https:// dx.doi.org/10.4067/S0718-22442013000200002

Wallerstein, I. (1974). El moderno sistema mundial. La agricultura capitalista y los orígenes de la economía-mundo europea en el siglo XVI. México, D.F.: Siglo XXI.

Wallerstein, I. (2005). Análisis de sistemas-mundo. Una introducción. México, D.F.: Siglo XXI.

Wallerstein, I. y Balibar, E. (1988). Raza, nación y clase. Madrid: Instituto de Estudios Políticos para América Latina y África, IEPALA.

Walsh, C. (2008). Interculturalidad, plurinacionalidad y decolonialidad: las insurgencias político-epistémicas de refundar el Estado. Revista Tabula Rasa, 9, 131-152. Recuperado de http://www. scielo.org.co/scielo.php?script=sci_arttext\&pid=S179424892008000200009\&lng=en\&tlng=es

Wieviorka, M. (1994). Racismo y exclusión. Estudios sociológicos, 12(34), 37-47. Recuperado de https://estudiossociologicos. colmex.mx/index.php/es/article/view/997/997 